\title{
$\alpha$-Linolenic acid but not conjugated linolenic acid is hypocholesterolaemic in hamsters
}

\author{
Lin Yang ${ }^{1,2}$, Ka Yiu Leung ${ }^{2}$, Ying Cao ${ }^{1}$, Yu Huang ${ }^{3}$, W. M. N. Ratnayake ${ }^{4}$ and Zhen-Yu Chen ${ }^{2} *$ \\ ${ }^{1}$ College of Chemistry \& Environmental Science, Henan Normal University, Henan, China \\ ${ }^{2}$ Food \& Nutritional Science Programme of Department of Biochemistry, The Chinese University of Hong Kong, Shatin, NT, Hong Kong, \\ China \\ ${ }^{3}$ Department of Physiology, The Chinese University of Hong Kong, Shatin, NT, Hong Kong, China \\ ${ }^{4}$ Nutrition Research Division, Food Directorate, Health Protection Branch, Health Canada, Ottawa, Ontario, Canada
}

(Received 11 August 2004 - Revised 27 October 2004 - Accepted 1 November 2004)

\begin{abstract}
Conjugated linolenic acid (CLN) refers to a group of octadecatrienoic acid isomers that have three double bonds in conjugation. Both pomegranate and tung seed oils are rich in CLN but the major isomer in the former is cis 9 ,trans 11 ,cis 13 while in the latter it is cis 9 ,trans 11 ,trans 13 . The present study examined the effects of CLN, isolated from either pomegranate seed oil or tung seed oil, and $\alpha$-linolenic acid (LN), isolated from flaxseed oil, on serum cholesterol levels in male hamsters (body weight $105 \mathrm{~g}$; age 10 weeks) fed a $0 \cdot 1 \%$ cholesterol and $10 \%$ lard diet, for a period of 6 weeks. All hamsters were allowed free access to food and fluid. The blood samples were taken by bleeding from the retro-orbital sinus into a heparinized capillary tube under light ether anaesthesia after overnight fasting at weeks $0,2,4$ and 6 . It was found that supplementation of CLN at levels of $12 \cdot 2-12 \cdot 7 \mathrm{~g} / \mathrm{kg}$ diet exhibited no significant effect on serum cholesterol level while LN at a similar level of supplementation had serum cholesterol reduced by $17-21 \%$ compared with the control diet containing no LN and CLN. Supplementation of CLN and LN significantly decreased hepatic cholesterol but no effect was observed on heart and kidney cholesterol levels. It was concluded that LN possessed hypocholesterolaemic activity while CLN had no effect on blood cholesterol, at least in hamsters.
\end{abstract}

Cholesterol: Conjugated linolenic acids: Octadecatrienoic acid: Pomegranate seed oil: Tung seed oil

Conjugated linolenic acid (CLN) is a generic term used to describe a group of positional and geometric isomers of octadecatrienoic acids that contains three double bonds in conjugation. Dietary intake of CLN by humans is currently unknown. Dietary CLN is quantitatively minor in the vegetable oils, accounting for up to $0.2 \%$ by weight (Yurawecz et al. 1993). The amount of CLN could be increased in partially hydrogenated soyabean oil and margarine (Mossoba et al. 1991). However, CLN in several kinds of seed oils, including tung seed oil, pomegranate seed oil, catalpa seed oil and karela seed oil, is present in large quantities and can account for $40-80 \%$ of total fatty acids (Takagi \& Itabashi, 1981; Suzuki et al. 2001). These seed oils contain a mixture of several CLN isomers, namely trans 9 ,trans 11 ,trans 13 $18: 3$, trans 9, trans 11, cis $13-18: 3$, cis 9, trans 11 ,trans $13-18: 3$, cis 9 ,trans 11, cis $13-18: 3$ and trans 8 ,trans 10, cis $12-18: 3$.

Interest in the biological activity of CLN is growing. Recent research has demonstrated that CLN is a potent suppressor on growth of various human tumour cells (Igarashi \& Miyazawa, 2000; Suzuki et al. 2001). In addition, CLN was found to be effective in reducing body fat mass in rats (Koba et al. 2002). It is known that dietary saturated, monounsaturated, polyunsaturated and trans-fatty acids affect blood cholesterol differently. However, information concerning the effect of CLN on blood cholesterol levels is limited and inconsistent. Dhar et al. (1999) found that CLN-enriched karela seed oil had no significant effect on the serum total cholesterol (TC) level in rats. However, in another study Dhar and Bhattacharyya (1998) demonstrated that rats fed with a CLN-enriched karela oil diet had serum TC and total triacylglycerol (TG) levels significantly higher than those fed an $\alpha$-linolenic acid (LN)enriched linseed oil diet. Similarly, Koba et al. (2002) found that supplementation of CLN in the free fatty acid form increased serum TG level compared with $\mathrm{LN}$ in rats. In recent years, hamsters have been more commonly used than rats as a model to study lipoprotein metabolism because, like humans, the major blood cholesterol carrier in hamsters is LDL, whereas in rats, most of its blood cholesterol occurs in HDL (Nistor et al. 1987; Lehmann et al. 1993). The present study was therefore carried out to examine further the effect of pure free CLN, isolated from either pomegranate seed oil or tung seed oil, on serum cholesterol levels, compared with that of $\mathrm{LN}$, isolated from flaxseed oil, in hamsters.

\footnotetext{
Abbreviations: CLA, conjugated linoleic acid; CLN, conjugated linolenic acid; HDL-C, high-density lipoprotein cholesterol; LDL-C, low-density lipoprotein cholesterol; LN, $\alpha$-linolenic acid; TC, total cholesterol; TG, triacylglycerols.

*Corresponding author: Dr Zhen-Yu Chen, fax +852 2603 7246, email zhenyuchen@cuhk.edu.hk
} 


\section{Materials and methods}

Isolation of conjugated linolenic acid from pomegranate and tung seed oils

Pomegranate seeds and tung seed oil were purchased from a local store at Xinxiang City, Henan, China. Pomegranate seeds were crushed into fine particles in a grinder and the oils were extracted using $n$-hexane followed by the removal of hexane in a rotary evaporator. Both pomegranate seed oil and tung oil were saponified in $1 \mathrm{M}-\mathrm{KOH}$ solution at $95^{\circ} \mathrm{C}$ under nitrogen. The saponified substances were saved and acidified to $\mathrm{pH} 1.0$ using $1 \mathrm{M}-\mathrm{H}_{2} \mathrm{SO}_{4}$. The top layer containing total free fatty acids was collected for further purification. CLN present in the total free fatty acids after saponification was purified by crystallization. The total free fatty acid fraction was warmed at $50^{\circ} \mathrm{C}$ and dissolved into methanol in a ratio of $1: 3(\mathrm{v} / \mathrm{v})$ in a flask. After flushing with nitrogen, the flask was placed into a $0-4^{\circ} \mathrm{C}$ refrigerator for $8 \mathrm{~h}$. The yellowish needle-shaped crystals containing mainly CLN were filtered and saved. The process was repeated twice until the CLN mixture reached $70 \%$ purity.

\section{Isolation of $\alpha$-linolenic acid from flaxseed}

Flaxseeds were crushed in a coffee grinder and the oils were extracted using a mixture of chloroform and methanol $(2: 1, \mathrm{v} / \mathrm{v})$. The solvents were removed in a rotary evaporator. The flaxseed oil $(130 \mathrm{~g})$ was then saponified in 2 litres of methanol containing $0 \cdot 3 \mathrm{M}-\mathrm{KOH}$ at $90^{\circ} \mathrm{C}$ under a gentle stream of $\mathrm{N}_{2}$ for $2 \mathrm{~h}$. After the removal of methanol in a rotary evaporator, the mixture was acidified to $\mathrm{pH} 1.0$ using $1 \mathrm{M}-\mathrm{H}_{2} \mathrm{SO}_{4}$. The top layer containing free fatty acids was washed three times with the same volume of distilled water. Isolation of LN was carried out using two-step crystallization. The free fatty acid mixture was dissolved into three volumes of methanol. The crystallization was carried out at $4^{\circ} \mathrm{C}$ to remove the saturated fatty acids and then at $-18^{\circ} \mathrm{C}$ to obtain $\mathrm{LN}$. The process was repeated twice until the $\mathrm{LN}$ fraction reached $80 \%$ purity.

\section{Fatty acid analysis}

LN and CLN were converted to the corresponding fatty acid methyl esters according to Igarashi et al. (2004). In brief, a $5 \mathrm{mg}$ sample was dissolved in $1 \mathrm{ml}$ toluene followed by adding $2 \mathrm{ml} \mathrm{14 \%} \mathrm{boron} \mathrm{trifluoride} \mathrm{in} \mathrm{methanol} \mathrm{(Sigma} \mathrm{Chemical} \mathrm{Co.,}$ St Louis, MO, USA). The mixture was flushed with a gentle stream of gas and maintained at room temperature for $30 \mathrm{~min}$, followed by adding $4 \mathrm{ml}$ hexane and $1 \mathrm{ml}$ distilled water. The hexane layer containing fatty acid methyl esters was analysed on a flexible silica capillary column (Innowax 19091N-213, $30 \mathrm{~m} \times 0.32 \mathrm{~mm}$ internal diameter; J\&W Scientific, Folsom, CA, USA) in a HP 5980 Series II gas-liquid chromatograph equipped with a flame-ionization detector (Hewlett-Packard, Palo Alto, CA, USA). Column temperature was programmed from 180 to $230^{\circ} \mathrm{C}$ at a rate of $2^{\circ} \mathrm{C} / \mathrm{min}$ and then held for $5 \mathrm{~min}$. Injector and detector temperatures were set at 250 and $300^{\circ} \mathrm{C}$, respectively. He gas was used as the carrier at a head pressure of $103 \mathrm{kPa}$. Identification of each fatty acid methyl ester was made by comparison of retention time of authentic standards (Sigma Chemical Co.). It was found that intra-isomerization of CLN species was minimal $(<1 \%)$ under the present experimental conditions (Igarashi et al. 2004).
Table 1. Composition of the control diet and the experimental diets supplemented with conjugated linolenic acids (CLN) obtained either from pomegranate seed oil (CLN-P) or tung oil (CLN-T) or with $\alpha$-linolenic acid purified from flaxseed oil (LN-F)

\begin{tabular}{lrccr}
\hline & \multicolumn{4}{c}{ Diets } \\
\cline { 2 - 5 } Component $(\mathrm{g} / \mathrm{kg})$ & Control & CLN-P & CLN-T & LN-F \\
\hline Cornstarch & 488 & 478 & 478 & 478 \\
Casein & 200 & 200 & 200 & 200 \\
Sucrose & 150 & 140 & 140 & 140 \\
Mineral mix (AIN-76) & 40 & 40 & 40 & 40 \\
Vitamin mix (AIN-76A) & 20 & 20 & 20 & 20 \\
DL-Methionine & 1 & 1 & 1 & 1 \\
Cholesterol & 1 & 1 & 1 & 1 \\
Lard & 100 & 100 & 100 & 100 \\
CLN-P & 0 & 20 & - & - \\
CLN-T & 0 & - & 20 & - \\
LN-F & 0 & - & - & 20 \\
\hline
\end{tabular}

\section{Diets}

The formula previously described by Zhang et al. (2002) was modified to prepare four diets for hamsters. The control diet was prepared by mixing all powdered ingredients and lard listed in Table 1. The CLN-P diet was prepared by mixing $20 \mathrm{~g} / \mathrm{kg}$ CLN, isolated from pomegranate seed oil, with the other ingredients. Similarly, the CLN-T diet was prepared except for adding $20 \mathrm{~g} / \mathrm{kg}$ CLN isolated from tung seed oil while the LN-F diet was prepared by using $20 \mathrm{~g} / \mathrm{kg} \mathrm{LN}$ isolated from flaxseed oil. All four powdered diets were then mixed with a gelatin solution $(20 \mathrm{~g} / \mathrm{l})$ in a ratio of $200 \mathrm{~g}$ diet per litre of solution. Once the gelatin had set, the diets were cut into approximately $20 \mathrm{~g}$ cubic portions and stored frozen $\left(-20^{\circ} \mathrm{C}\right)$.

\section{Animals}

Forty-eight male Golden Syrian hamsters (Mesocricetus auratus, $105 \pm 5 \mathrm{~g}, 10$ weeks; Laboratory Animal Service Center, The Chinese University of Hong Kong) were divided into four groups $(n$ 12) fed one of the four diets. All hamsters were housed (two per cage) in an animal room at $23^{\circ} \mathrm{C}$ with $12 / 12 \mathrm{~h}$ light-dark cycles. The fresh diets were given daily, and uneaten food was discarded. Food intake was measured daily and body weight was recorded twice a week. The hamsters were given free access to food and fluid. The protocol was reviewed and approved by the Committee of Animal Ethics, The Chinese University of Hong Kong. All the hamsters were bled from the retroorbital sinus into a heparinized capillary tube under light ether anaesthesia after overnight fasting at weeks $0,2,4$ and 6 (Chan et al. 1999). After clotting, the blood was centrifuged at $1500 \mathrm{~g}$ for $10 \mathrm{~min}$ and serum was collected. At the end of week 6 , all the hamsters were killed; liver, heart, kidney and adipose tissues (epididymal and prerenal pads) were removed, washed in saline, weighed and frozen in liquid $\mathrm{N}_{2}$. All samples were stored frozen at $-80^{\circ} \mathrm{C}$ prior to cholesterol analysis.

\section{Serum lipids}

Serum TC and TG levels were determined enzymatically by using commercial kits (Sigma Chemical Co.). High-density lipoprotein cholesterol (HDL-C) was measured after precipitation of LDL and VLDL with phosphotungstic acid and magnesium chloride 
(Sigma Chemical Co.). Non-high-density lipoprotein cholesterol (non-HDL-C) was calculated by deducting HDL-C from the TC.

\section{Determination of cholesterol in liver, heart and adipose tissues}

Total lipids were extracted from $300 \mathrm{mg}$ of tissue sample with the addition of $1 \mathrm{mg}$ stigmastanol as an internal standard, using $15 \mathrm{ml}$ chloroform-methanol $(2: 1, \mathrm{v} / \mathrm{v})$. The lipid extracts were then saponified with $6 \mathrm{ml} 1 \mathrm{M}-\mathrm{NaOH}$ in $90 \%$ ethanol at $90^{\circ} \mathrm{C}$ for $1 \mathrm{~h}$, and the non-saponified substances including cholesterol were then converted to their trimethylsilyl-ether derivatives by a commercial trimethylsilyl reagent (Sigma Chemical Co.). Analysis of the cholesterol trimethylsilyl-ether derivative was performed in a fused silica capillary column $\left(\mathrm{SAC}^{\mathrm{TM}}-5,30 \mathrm{~m} \times 0.25 \mathrm{~mm}\right.$ internal diameter; Supelco Inc., Bellefonte, PA, USA) in a Shimadzu GC14B GLC equipped with a flame-ionization detector (Shimadzu, Tokyo, Japan). The column temperature was set at $285^{\circ} \mathrm{C}$ and maintained for $30 \mathrm{~min}$. He gas was used as carrier at a head pressure of $150 \mathrm{kPa}$. Cholesterol in the tissue sample was calculated according to the amount of internal standard stigmastanol added (Chan et al. 1999).

\section{Statistics}

Data are expressed as means with their standard deviations. Where applicable, ANOVA was used to evaluate statistically significant differences among the control, CLN-P, CLN-T and LN-F groups using Sigmastat (Jandel Scientific Software, San Rafael, CA, USA). Subsequently, Student's $t$ test was used to compare the difference between any two groups. Differences were considered significant at $P<0 \cdot 05$.

\section{Results}

Fatty acid composition of dietary fat

The fatty acid content was expressed as $\mathrm{g} / \mathrm{kg}$ diet (Table 2). CLN$\mathrm{P}$ and CLN-T had $12.2-12.7 \mathrm{~g}$ CLN/kg diet in contrast to the LN-F diet which had no CLN but had $13.3 \mathrm{~g} \mathrm{LN} / \mathrm{kg}$ diet. The other fatty acids among the two CLN experimental diets were similar except that the major CLN isomer in the CLN-P diet

Table 2. Fatty acid composition ( $\mathrm{g} / \mathrm{kg}$ diet) of the control diet and the experimental diets supplemented with conjugated linolenic acids (CLN) obtained either from pomegranate seed oil (CLN-P) or tung oil (CLN-T) or with $\alpha$-linolenic acid purified from flaxseed oil (LN-F)

\begin{tabular}{lcrrr}
\hline & \multicolumn{4}{c}{ Diet } \\
\cline { 2 - 5 } & Control & CLN-P & CLN-T & LN-F \\
\hline $14: 0$ & $1 \cdot 7$ & $1 \cdot 7$ & $1 \cdot 8$ & $1 \cdot 8$ \\
$16: 0$ & $23 \cdot 9$ & $25 \cdot 8$ & $26 \cdot 2$ & $25 \cdot 5$ \\
$16: 1 n-7$ & $2 \cdot 7$ & $2 \cdot 8$ & $2 \cdot 9$ & $2 \cdot 7$ \\
$18: 0$ & $11 \cdot 7$ & $12 \cdot 7$ & $12 \cdot 7$ & $11 \cdot 6$ \\
$18: 1 n-9$ & $38 \cdot 9$ & $40 \cdot 9$ & $41 \cdot 2$ & $42 \cdot 9$ \\
$18: 2 n-6$ & $13 \cdot 7$ & $14 \cdot 6$ & $14 \cdot 9$ & $14 \cdot 8$ \\
$18: 3 n-3$ & $0 \cdot 8$ & $0 \cdot 9$ & $0 \cdot 8$ & $13 \cdot 4$ \\
CLN & 0 & $12 \cdot 7$ & $12 \cdot 2$ & 0 \\
cis9,trans11, cis13-18:3 & 0 & $10 \cdot 8$ & 0 & 0 \\
cis9, trans11,trans13-18:3 & 0 & $1 \cdot 1$ & $10 \cdot 0$ & 0 \\
trans9, trans11, cis13-18:3 & 0 & $0 \cdot 7$ & $0 \cdot 2$ & 0 \\
trans9, trans11,trans13-18:3 & 0 & $0 \cdot 2$ & $2 \cdot 0$ & 0 \\
Others & $1 \cdot 2$ & $1 \cdot 2$ & $1 \cdot 2$ & $1 \cdot 3$ \\
\hline
\end{tabular}

was cis 9 ,trans 11 , cis 13 while CLN-T contained mainly cis 9 ,trans11,trans 13 .

\section{Body weight and food intake}

The changes in the body weight and food intake of the hamsters are demonstrated in Table 3. No significant differences in body weight gain were observed although the CLN-P group had a smaller average body weight compared to the other three groups. Similarly, there were no significant differences in food intakes among the four groups but it appeared that the CLN-P group had a food intake slightly lower than the other three groups. The organ weights were similar among the four groups except that the LN-F group had smaller liver and heart than the control group.

\section{Serum TC, HDL-C, TG and non- $H D L-C / H D L-C$}

Four groups had similar levels of serum TC, HDL-C and TG at the beginning of the experiment (Table 4). At the end of week 2 , the serum TC level of the LN-F group started to be significantly lower compared with those of the other three groups. This was mainly caused by lowering of the non-HDL-C level in the LN$\mathrm{F}$ group, thus leading to a lower ratio of non-HDL-C to HDL-C (Table 4). No significant differences in serum TC, HDL-C, nonHDL-C and TG were observed among the control, CLN-P and CLN-T groups. The serum TG level in hamsters fed the LN-F diet was the lowest during the 6-week feeding. In general, supplementation of CLN either from pomegranate seed oil or tung seed oil did not cause any significant change in serum TC level compared with the control, but addition of $\mathrm{LN}$ to the diet led to reduced TC and non-HDL-C levels.

\section{Liver, heart and kidney cholesterol}

Supplementation with CLN and LN significantly decreased the hepatic cholesterol level but not heart and kidney cholesterol levels (Table 5). However, no significant differences in hepatic cholesterol among the three experiment groups could be observed. The LN-F group had an adipose tissue cholesterol level significantly lower than the other three groups (Table 5). No difference in adipose tissue cholesterol levels was seen among the control, CLN-P and CLN-T groups.

\section{Discussion}

The present study examined the effect of CLN supplementation on the serum lipid profile compared with that of LN in hamsters. The results clearly demonstrated that $\mathrm{LN}$ possessed a favourable effect but CLN had no effect on serum lipids. The observation is in agreement with that reported by Dhar et al. (1999), who found that supplementation of $0 \cdot 5,2$ and $10 \%$ CLN derived from karela oil in the diet had no effect on blood TC, HDL-C and non-HDL-C levels, compared with the linoleic acid-enriched sunflower oil diet in rats. Instead, addition of CLN-enriched karela oil in the diet led to increased levels of serum TC, TG, VLDL-C, LDL-C and LDL/HDL-C in rats if compared with an LN-enriched linseed oil diet (Dhar \& Bhattacharyya, 1998). In both tung seed oil and karela seed oil, cis9,trans 11 ,trans $13-$ $18: 3$ is the major isomer. In the present study, it accounted for $10 \mathrm{~g} / \mathrm{kg}$ diet for hamsters whereas in the study by Dhar et al. 
Table 3. Body weight, organ weight and food intake in hamsters fed the control diet and the experimental diets supplemented with conjugated linolenic acids (CLN) obtained either from pomegranate seed oil (CLN-P) or tung oil (CLN-T) or with $\alpha$-linolenic acid purified from flaxseed oil (LN-F)

(Mean values with their standard deviations)

\begin{tabular}{|c|c|c|c|c|c|c|c|c|}
\hline & \multicolumn{2}{|c|}{ Control } & \multicolumn{2}{|c|}{ CLN-P } & \multicolumn{2}{|c|}{ CLN-T } & \multicolumn{2}{|c|}{ LN-F } \\
\hline & Mean & SD & Mean & SD & Mean & SD & Mean & SD \\
\hline Initial body wt (g) & $105 \cdot 5$ & 5.5 & $106 \cdot 0$ & $9 \cdot 7$ & $104 \cdot 0$ & $5 \cdot 7$ & $104 \cdot 2$ & $6 \cdot 0$ \\
\hline Final body wt (g) & $135 \cdot 4$ & $5 \cdot 0$ & $128 \cdot 9$ & $10 \cdot 2$ & $132 \cdot 7$ & $8 \cdot 1$ & $130 \cdot 7$ & $10 \cdot 3$ \\
\hline Food intake $(\mathrm{g} / \mathrm{d})$ & $9 \cdot 5$ & $0 \cdot 1$ & $9 \cdot 0$ & 0.1 & $10 \cdot 4$ & 0.6 & $9 \cdot 7$ & 0.5 \\
\hline Liver $(g)$ & $5 \cdot 5^{a}$ & 0.3 & $5 \cdot 2^{a b}$ & 0.8 & $5 \cdot 1^{\mathrm{b}}$ & 0.5 & $5 \cdot 0^{b}$ & 0.6 \\
\hline Heart $(\mathrm{g})$ & $0.5^{a}$ & 0.1 & $0.5^{\mathrm{a}}$ & $0 \cdot 1$ & $0.5^{\mathrm{a}}$ & 0.3 & $0.4^{b}$ & $0 \cdot 1$ \\
\hline Kidney (g) & $1 \cdot 1$ & $0 \cdot 1$ & $1 \cdot 1$ & 0.1 & $1 \cdot 2$ & 0.2 & $1 \cdot 1$ & 0.1 \\
\hline Brain (g) & 0.9 & 0.1 & 0.9 & 0.1 & 0.9 & 0.1 & 0.9 & 0.1 \\
\hline
\end{tabular}

${ }^{a, b}$ Mean values in a row with different letters differ significantly at $P<0.05$.

(1999) it ranged from 5 to $100 \mathrm{~g} / \mathrm{kg}$ diet for rats. In this regard, it is clear that no favourable effect on the blood lipoprotein profile is associated with supplementation of CLN in both rats and hamsters. Pomegranate and tung seed oils have different CLN isomer profiles. The former has cis 9 ,trans 11 , cis 13-18:3 dominant whereas in the latter cis 9 ,trans 11 ,trans $13-18: 3$ is predominant. The present study found that both CLN-P and CLN-T groups had similar serum and hepatic cholesterol levels, indicating these two isomers did not have different effects on cholesterol metabolism. Together with the previous studies of Dhar \& Bhattacharyya (1998) and Dhar et al. (1999), it can be concluded that CLN is not hypocholesterolaemic, regardless of whether it is present in the form of either triacylglycerol or free fatty acid.
The number of conjugated double bonds may affect significantly the cholesterol-lowering properties of a conjugated fatty acid. This view is best illustrated when the effect of CLN on blood cholesterol was compared with that of conjugated linoleic acids (CLA), a group of conjugated octadecadienoic acid isomers. The former has three double bonds while the latter contains two double bonds in conjugation. CLA was found to possess antiatherosclerotic activity when rabbits and hamsters were fed a high cholesterol diet (Lee et al. 1994; Nicolosi et al. 1997). Like its unconjugated isomer linoleic acid, CLA has also been demonstrated to reduce serum cholesterol levels in hamsters fed a high cholesterol diet (Nicolosi et al. 1997; Yeung et al. 2000). However, this was not true for CLN and LN; the former had no

Table 4. Changes in serum total cholesterol (TC), total triacylglycerols (TG), high-density lipoprotein cholesterol (HDL-C) and non-HDL-C/HDL-C in hamsters fed the control diet and the experimental diets supplemented with conjugated linolenic acids (CLN) obtained either from pomegranate seed oil (CLN-P) or tung oil (CLN-T) or supplemented with $\alpha$-linolenic acid purified from flaxseed oil (LN-F)

(Mean values and their standard deviations)

\begin{tabular}{|c|c|c|c|c|c|c|c|c|}
\hline & \multicolumn{2}{|c|}{ Control } & \multicolumn{2}{|c|}{ CLN-P } & \multicolumn{2}{|c|}{ CLN-T } & \multicolumn{2}{|c|}{ LN-F } \\
\hline & Mean & SD & Mean & SD & Mean & SD & Mean & SD \\
\hline \multicolumn{9}{|l|}{ Week 0} \\
\hline $\mathrm{TC}(\mathrm{mmol} / \mathrm{l})$ & $3 \cdot 28$ & 0.35 & $3 \cdot 19$ & 0.20 & $3 \cdot 20$ & 0.32 & $3 \cdot 26$ & 0.37 \\
\hline $\mathrm{HDL}-\mathrm{C}(\mathrm{mmol} / \mathrm{l})$ & 1.52 & 0.14 & 1.52 & 0.15 & 1.46 & 0.11 & 1.52 & 0.16 \\
\hline Non-HDL-C & $1 \cdot 76$ & 0.29 & 1.67 & 0.25 & 1.74 & 0.38 & $1 \cdot 74$ & 0.36 \\
\hline $\mathrm{TG}(\mathrm{mmol} / \mathrm{l})$ & $2 \cdot 19$ & 0.22 & 1.88 & 0.54 & $2 \cdot 12$ & 0.31 & 1.97 & 0.33 \\
\hline Non-HDL-C/HDL-C & $1 \cdot 16$ & 0.23 & $1 \cdot 10$ & 0.26 & $1 \cdot 19$ & 0.36 & $1 \cdot 14$ & 0.33 \\
\hline \multicolumn{9}{|l|}{ Week 2} \\
\hline $\mathrm{TC}(\mathrm{mmol} / \mathrm{l})$ & $4 \cdot 74^{\mathrm{a}}$ & 0.53 & $4.55^{\mathrm{a}}$ & 0.83 & $4 \cdot 39^{a}$ & 0.49 & $3 \cdot 83^{\mathrm{b}}$ & 0.36 \\
\hline $\mathrm{HDL}-\mathrm{C}(\mathrm{mmol} / \mathrm{l})$ & $3 \cdot 16$ & 0.34 & 3.39 & 0.61 & 3.06 & 0.54 & 2.97 & 0.29 \\
\hline Non-HDL-C & $1.48^{\mathrm{a}}$ & 0.64 & $1 \cdot 26^{\mathrm{a}}$ & 0.53 & $1 \cdot 33^{a}$ & 0.49 & $0.86^{\mathrm{b}}$ & 0.30 \\
\hline $\mathrm{TG}(\mathrm{mmol} / \mathrm{l})$ & $6 \cdot 23^{a}$ & $2 \cdot 01$ & $6 \cdot 66^{\mathrm{a}}$ & $2 \cdot 76$ & $5 \cdot 42^{\mathrm{ab}}$ & 1.73 & $4.09^{\mathrm{b}}$ & 1.73 \\
\hline Non-HDL-C/HDL-C & $0.47^{\mathrm{a}}$ & 0.19 & $0.37^{\mathrm{ab}}$ & $0 \cdot 15$ & $0.43^{\mathrm{a}}$ & 0.24 & $0.29^{b}$ & 0.12 \\
\hline \multicolumn{9}{|l|}{ Week 4} \\
\hline TC (mmol/l) & $5 \cdot 34^{a}$ & 0.73 & $5 \cdot 52^{\mathrm{a}}$ & 0.80 & $5 \cdot 39^{a}$ & 0.79 & $4 \cdot 45^{\mathrm{b}}$ & 0.42 \\
\hline $\mathrm{HDL}-\mathrm{C}(\mathrm{mmol} / \mathrm{l})$ & $2 \cdot 77$ & 0.34 & $2 \cdot 83$ & 0.33 & $2 \cdot 70$ & 0.24 & 2.55 & 0.24 \\
\hline Non-HDL-C & $2 \cdot 57^{\mathrm{a}}$ & 0.49 & $2 \cdot 69^{a}$ & 0.59 & $2 \cdot 69^{a}$ & 0.64 & $1.90^{\mathrm{b}}$ & 0.16 \\
\hline $\mathrm{TG}(\mathrm{mmol} / \mathrm{l})$ & $6 \cdot 03^{\mathrm{a}}$ & $1 \cdot 38$ & $4 \cdot 67^{\mathrm{ab}}$ & $2 \cdot 12$ & $5 \cdot 31^{b}$ & $2 \cdot 08$ & $3 \cdot 88^{\mathrm{b}}$ & 1.07 \\
\hline Non-HDL-C/HDL-C & $0.93^{\mathrm{a}}$ & 0.19 & $0.95^{\mathrm{a}}$ & 0.18 & $1.00^{\mathrm{a}}$ & 0.22 & $0.75^{\mathrm{b}}$ & 0.13 \\
\hline \multicolumn{9}{|l|}{ Week 6} \\
\hline $\mathrm{TC}(\mathrm{mmol} / \mathrm{l})$ & $5 \cdot 41^{\mathrm{a}}$ & 0.75 & $5 \cdot 26^{a}$ & 0.88 & $5 \cdot 07^{\mathrm{a}}$ & 0.58 & $4 \cdot 28^{\mathrm{b}}$ & 0.39 \\
\hline $\mathrm{HDL}-\mathrm{C}(\mathrm{mmol} / \mathrm{l})$ & $2.95^{\mathrm{a}}$ & 0.41 & $2 \cdot 86^{\mathrm{a}}$ & $0.37^{a}$ & $2 \cdot 90^{\mathrm{a}}$ & 0.42 & $2 \cdot 59^{\mathrm{b}}$ & 0.36 \\
\hline Non-HDL-C & $2 \cdot 46^{\mathrm{a}}$ & 0.56 & $2 \cdot 40^{\mathrm{a}}$ & 0.68 & $2 \cdot 37^{\mathrm{a}}$ & 0.48 & $1.69^{\mathrm{b}}$ & 0.27 \\
\hline $\mathrm{TG}(\mathrm{mmol} / \mathrm{l})$ & $5 \cdot 09^{a}$ & $1 \cdot 16$ & $4 \cdot 40^{\mathrm{a}}$ & 1.62 & $4.53^{a}$ & $1 \cdot 26$ & $3 \cdot 71^{\mathrm{b}}$ & 1.45 \\
\hline Non-HDL-C/HDL-C & $0.83^{\mathrm{a}}$ & 0.25 & $0.84^{a}$ & 0.24 & $0.82^{a}$ & 0.25 & $0.65^{\mathrm{b}}$ & 0.16 \\
\hline
\end{tabular}

\footnotetext{
a,b Mean values in a row for a given week with different letters differ significantly at $P<0.05$.
} 
Table 5. Cholesterol content $(\mathrm{mg} / \mathrm{g})$ of the liver, heart and kidney in hamsters fed the experimental diets supplemented with conjugated linolenic acids (CLN) obtained either from pomegranate seed oil (CLN-P) or tung oil (CLN-T) or with $\alpha$-linolenic acid purified from flaxseed oil (LN-F)

(Mean values and their standard deviations)

\begin{tabular}{|c|c|c|c|c|c|c|c|c|}
\hline & \multicolumn{2}{|c|}{ Control } & \multicolumn{2}{|c|}{ CLN-P } & \multicolumn{2}{|c|}{ CLN-T } & \multicolumn{2}{|c|}{ LN-F } \\
\hline & Mean & SD & Mean & SD & Mean & SD & Mean & SD \\
\hline Liver & $50 \cdot 2^{a}$ & $3 \cdot 2$ & $30 \cdot 4^{b}$ & 4.6 & $29 \cdot 3^{b}$ & 4.9 & $35 \cdot 5^{\mathrm{b}}$ & $6 \cdot 3$ \\
\hline Heart & $2 \cdot 8$ & 1.0 & $3 \cdot 8$ & 0.4 & $2 \cdot 8$ & 1.0 & 2.5 & 0.8 \\
\hline Kidney & $3 \cdot 7$ & 0.3 & $4 \cdot 1$ & 0.4 & 3.8 & 0.1 & 3.9 & 0.2 \\
\hline Adipose tissue & $0.9^{a}$ & 0.1 & $0.9^{a}$ & 0.1 & $0.9^{a}$ & 0.1 & $0.7^{\mathrm{b}}$ & 0.1 \\
\hline
\end{tabular}

a,b Mean values in a row with different letters differ significantly at $P<0.05$.

effect while the latter was hypolipidaemic, as shown in the present study. There is no study to date that has investigated why conjugated octadecadienoic acids and conjugated octadecatrienoic acids affect cholesterol metabolism differently.

The mechanism by which LN but not CLN is hypocholesterolaemic remains poorly understood. Longer chain $n-3$ fatty acids do not usually lower serum cholesterol (Harris, 1997; Minihane et al. 2000; Theobald et al. 2004) but LN has been reported to do so (Bjerve et al. 1989; Chan et al. 1991). The present study confirmed the hypocholesterolaemic activity of LN (Table 4). The cholesterol-lowering effect of $\mathrm{LN}$ is most likely mediated by suppression on cholesterogenesis in inhibiting both enzymatic activity and mRNA expression of hepatic 3-hydroxy-3-methylglutaryl CoA reductase (Ihara-Watanabe et al. 1998). Although feeding $n$-3 fatty acids derived from fish oil was associated with an increase in LDL receptor activity (Ventura et al. 1989; Spady, 1993), incorporation of $\mathrm{LN}$ in the diet appeared to have no such suppressive effect on mRNA of the LDL receptor (Spady, 1993; Fukushima et al. 2001; Morise et al. 2004). It will be interesting if future studies can investigate the mechanism of why non-conjugated octadecatrienoic acid is hypolipidaemic but conjugated octadecatrienoic acid has no such activity by examining specifically any difference in the effect of dietary CLN and LN on the LDL receptor and 3-hydroxy-3-methylglutaryl CoA reductase.

CLN did not affect the serum cholesterol level but it decreased the hepatic cholesterol level (Table 5). In contrast, LN decreased not only serum TC but also the hepatic cholesterol level (Table 5). The effect of LN was similar to that of CLA, which had been shown to decrease cholesterol levels in both serum and liver (Yeung et al. 2000). CLA also increased the cholesterol level in adipose tissue (Yeung et al. 2000) while no change in the cholesterol level of adipose tissue was observed in the present study when CLN was added to the diet (Table 4). More interesting was that LN reduced the cholesterol level in adipose tissue (Table 4), suggesting that interactions of dietary CLN, LN and CLA with cholesterol metabolism are different in many ways and deserve further investigation.

Intake of dietary CLN is mainly from consumption of the processed vegetable oils. CLN is formed during the processing of vegetable oils as result of the dehydration of secondary oxidation products of linoleic acid (Yurawecz et al. 1993). When twentyseven vegetable oils were analysed, it was found that the level of CLN ranged from not being detected $(<0.001 \%)$ to $0.2 \%$ by weight (Yurawecz et al. 1993). It was also reported that CLN could be produced by isomerization of its non-conjugated isomer, $\mathrm{LN}$, when LN-containing vegetable oils were partially hydrogenated in the production of shortenings and margarines
(Mossoba et al. 1991). To date, there is no report that has estimated the current intake of CLN by humans and it is also not certain if CLN has health benefits similar to those of CLA and LN.

\section{Acknowledgement}

We thank the Hong Kong Research Grant Council for supporting this research.

\section{References}

Bjerve KS, Fisher S \& Wammer F (1989) Alpha-linolenic acid and long chain omega-3 fatty acids supplementation in three patients with omega-3 deficiency: effect on lymphocyte function, plasma and red cell lipids and prostanoid formation. Am J Clin Nutr 49, 290-300.

Chan JK, Bruce VM \& McDonald BE (1991) Dietary alpha-linolenic acid is as effective as oleic acid and linoleic acid in lowering blood cholesterol in normolipidemic men. Am Clin Nutr 53, 1230-1234.

Chan PT, Fong WP, Cheung YL, Huang Y, Ho WKK \& Chen ZY (1999) Jasmine green epicatechins are hypolipidemic in hamsters fed a high fat diet. J Nutr 129, 1094-1101.

Dhar P \& Bhattacharyya DK (1998) Nutritional characteristics of oil containing conjugated octadecatrienoic fatty acid. Ann Nutr Metab 42, 290-296.

Dhar P, Ghosh S \& Bhattacharyya DK (1999) Dietary effects of conjugated octadecatrienoic fatty acid (9cis,11trans,13trans) levels on blood lipids and nonenzymatic in vitro lipid peroxidation in rats. Lipids 34, 109-114.

Fukushima M, Ohhashi T, Ohno S, Saitoh H, Sonoyama K, Shimada K, Sekijawa M \& Makano M (2001) Effect of diets enriched in n-6 or n-3 fatty acids on cholesterol metabolism in order rats chronically fed a cholesterol-enriched diet. Lipids 36, 261-266.

Harris WS (1997) n-3 Fatty acids and serum lipoproteins: human studies. Am J Clin Nutr 65, 645-654

Igarashi M \& Miyazawa T (2000) New recognized effect of conjugated trienoic fatty acids on cultured human tumor cells. Cancer Lett 148, $173-179$.

Igarashi M, Tsuzuki T, Kambe T \& Miyazawa T (2004) Recommended methods of fatty acid methylester preparation for conjugated dienes and trienes in food and biological samples. J Nutr Sci Vitaminol 50, $121-128$.

Ihara-Watanabe M, Umekawa H, Takahashi T \& Furuichi Y (1998) Effect of dietary alpha- or gamma-linolenic acid on levels and fatty acid composition of serum and hepatic lipids, and activity and mRNA abundance of 3-hydroxy-3-methylglutaryl CoA reductase in rats. Comp Biochem Physiol A Mol Integr Physiol 122, 213-220.

Koba K, Akahoshi A, Yamasaki M, Tanaka K, Yamada K, Iwata T, Kamegai T, Tsutsmi K \& Sugano K (2002) Dietary conjugated linoleic acid in relation to CLA differently modified body fat mass and serum and liver lipid levels in rats. Lipids 37, 343-350. 
Lee KN, Kritchevsky D \& Pariza MW (1994) Conjugated linoleic acid and atherosclerosis in rabbits. Atherosclerosis 108, 19-25.

Lehmann R, Bhargava AS \& Gunzel P (1993) Serum lipoprotein pattern in rats, dogs, and monkeys, including method comparison and influence of menstrual cycle in monkeys. Eur J Clin Chemi Clin Biochem 31, 633-637.

Minihane AM, Khan S, Leigh-Firbank EC, Talmud P, Wright JW, Murphy MC, Griffin BA \& Williams CM (2000) ApoE polymorphism and fish oil supplementation in subjects with an atherogenic lipoprotein phenotype. Arterioscler Thromb Vasc Biol 20, 1990-1997.

Morise A, Serougne C, Hripois D, Blougquit MF, Lutton C \& Hermier D (2004) Effect of dietary alpha linolenic acid on cholesterol metabolism in male and female hamsters of the LPN strain. J Nutr Biochem 15, 51-61.

Mossoba MM, McDonald RE, Armstrong DJ \& Page SW (1991) Identification of minor $\mathrm{C} 10$ triene and conjugated diene isomer in hydrogenated soybean oil and margarine by GC-MI-FT and IR spectroscopy. $J$ Chromatogr Sci 29, 324-333.

Nicolosi RJ, Rogers EJ, Kritchevsky D, Scimeca JA \& Huth PJ (1997) Dietary conjugated linoleic acid reduces plasma lipoproteins and early aortic atherosclerosis in hypercholesterolemic hamsters. Artery 22, 266-277.

Nistor A, Bulla A, Fillip DA \& Radu A (1987) The hyperlipidemic hamster as a model of experimental atherosclerosis. Atherosclerosis 68, 159-173.

Spady DK (1993) Regulatory effects of individual n-6 and n-3 polyunsaturated fatty acids on LDL transport in the rat. J Lipid Res 34, 1337-1346.

Suzuki R, Noguchi R, Ota T, Abe M, Miyashita K \& Kawada T (2001) Cytotoxic effect of conjugated trienoic fatty acids on mouse tumor and human monocytic leukaemia cells. Lipids 36, 477-482.

Takagi T \& Itabashi Y (1981) Occurrence of mixtures of geometrical isomers of conjugated octadecatrienoic acids in some seed oils: analysis by open tubular gas liquid chromatography and high performance liquid chromatography. Lipids 16, 546-551.

Theobald HE, Chowienczyk PJ, Whittall R, Humphries SE \& Sanders TAB (2004) LDL cholesterol-raising effect of low-dose docosahexaenoic acid in middle-aged men and women. Am J Clin Nutr 79, 558-563.

Ventura MA, Wollett LA \& Spady DK (1989) Dietary fish oil stimulates hepatic low-density lipoprotein transport in the rats. J Clin Invest 84, 528-537.

Yeung CHY, Yang L, Huang Y, Wang J \& Chen ZY (2000) Dietary conjugated linoleic acid mixture affects the activity of intestinal acyl coenzyme A: cholesterol acyltransferase in hamsters. $\mathrm{Br} J$ Nutr 4, 935-941

Yurawecz MP, Molina AA, Mossoba M \& Ku Y (1993) Estimation of conjugated octadecatrienes in edible fats and oils. J Am Oil Chem Soc 70, 1093-1099.

Zhang Z, Yeung WK, Huang Y \& Chen ZY (2002) Effect of squalene and shark liver oil on serum cholesterol level in hamsters. Int J Food Sci Nutr 53, 411-418. 